\title{
THE MORAL CLOSURE ARGUMENT
}

\author{
Matt Lutz
}

SKEPTICAL HYPOTHESIS ARGUMENT introduces a scenario-a skeptical
hypothesis-where our beliefs about some subject matter are systemat-
ically false, but our experiences do not discriminate between the case where our beliefs are true and the skeptical scenario where they are not. Because we are unable to rule out this scenario, we do not know that any of our beliefs about the subject matter are true. As one famous skeptical hypothesis argument goes: I cannot rule out the hypothesis that I am being deceived by a demon. Therefore, I cannot know anything about the external world. By similar token, a moral skeptical hypothesis argument is an argument that moral knowledge is impossible for agents like us in situations like ours, because we are unable to rule out some skeptical hypothesis.

In this paper, I will defend a moral skeptical hypothesis argument-the Moral Closure Argument-against a number of objections. This argument is not novel, but it has rarely been taken seriously because it is widely held that the argument has serious flaws. My task in this paper is to argue that these supposed flaws are merely apparent; the Moral Closure Argument is much more potent than it might seem.

\section{THE MORAL CLOSURE ARGUMENT}

Let us introduce a few of the concepts that will feature prominently in the discussion to come.

Closure: If $S$ knows that $P$, and $P$ entails $Q$ and $S$ believes that $Q$ on the basis of competently deducing $Q$ from $P$, while retaining knowledge of $P$ throughout his reasoning, then $S$ knows that $Q .{ }^{1}$

A closure argument is a kind of skeptical hypothesis argument that relies on Clo-

1 There are other ways to formulate Closure, but this is the most widely accepted version of the principle. For discussion, see Hawthorne, “The Case for Closure." I assume that Closure is true. 
sure (or an instance of the Closure schema) as a premise. To take one famous example: if I know that I have hands, then, by Closure, I would be in a position to know that I am not handless and, therefore, in a position to know that I am not a handless brain in a vat (BIV), or a handless dupe of an evil demon. But I am not in a position to know that I am not being deceived by an evil demon-for all I know, I could be deceived in this way. So, by modus tollens, I do not know I have hands. Call this the External World Closure Argument.

The second clause of Closure is "P entails Q." Accordingly, in the context of a closure argument, for knowledge of the commonsense proposition to yield knowledge of the falsity of the skeptical hypothesis the skeptical hypothesis must be a scenario where the proposition that is the subject of the skeptical challenge is false. Thus, for a skeptical hypothesis to feature in a closure argument, it must be the case that the skeptical hypothesis is inconsistent with the contested proposition. It follows that skeptical hypotheses are only skeptical relative to some proposition or another. The hypothesis that I am a recently envatted brain is a skeptical hypothesis relative to my beliefs about the external world (at the present time), but is not a skeptical hypothesis relative to my beliefs about the past. Conversely, the hypothesis that the world sprung into existence five minutes ago is a skeptical hypothesis relative to my beliefs about the past, but not relative to my beliefs about the present external world.

But skeptical hypotheses do more than stipulate that the proposition in question is false. Skeptical hypotheses also provide an explanation of our experiences that is consistent with the falsity of the contested subject matter. The evil demon hypothesis and the BIV hypothesis both provide explanations of my experiences (particularly, my sensory experiences) that are consistent with my beliefs about the external world being false; the five-minute-old-world hypothesis is an explanation of my experiences (particularly, my memory experiences) that is consistent with all my beliefs about the past being false. Let us call this second part of a skeptical hypothesis argument an experience generator.

Some epistemologists, like Stroud and Pryor, have argued that the first condition on a skeptical hypothesis, the falsity condition, is dispensable. ${ }^{2}$ For these epistemologists, a hypothesis can be a skeptical hypothesis even if it is consistent with the truth of the contested proposition. Accordingly, the only thing that is needed for a skeptical hypothesis is the experience generator. Call a skeptical hypothesis that consists in only an experience generator a compatible skeptical hypothesis, because such a skeptical hypothesis is compatible with the truth of the contested proposition. An incompatible skeptical hypothesis is one that is incompatible with the truth of the contested proposition. Only incompatible

2 Stroud, The Significance of Philosophical Scepticism; Pryor, “The Skeptic and the Dogmatist." 
skeptical hypotheses can feature in closure arguments, because only incompatible skeptical hypotheses present scenarios whose falsity is entailed by our commonsense beliefs. Because this paper is concerned with closure arguments, we will only consider incompatible skeptical hypotheses.

The distinction between the falsity stipulation and the experience generator of an incompatible skeptical hypotheses and the corresponding distinction between incompatible and compatible skeptical hypotheses will be important to many of the arguments to come. Bear them in mind.

\subsection{The Moral Closure Argument Explained}

The argument that I will defend here-the Moral Closure Argument-mimics the structure of the External World Closure Argument. But instead of showing that we have no external world knowledge, the argument instead shows that we have no moral knowledge. ${ }^{3}$ And instead of the BIV or evil demon hypotheses, the Moral Closure Argument selects a different skeptical hypothesis.

Sinnott-Armstrong, in his discussion of the Moral Closure Argument, holds that "moral nihilism" is a skeptical hypothesis relative to our moral beliefs. ${ }^{4}$ But that cannot be entirely correct. Moral nihilism—or, more precisely, moral error theory-is, by itself, not a skeptical hypothesis, anymore than the hypothesis "You don't have hands" is a skeptical hypothesis. Error theory must be part of any incompatible skeptical hypothesis relative to our moral beliefs because moral error theory is the only view in metaethics according to which our first-order moral beliefs are false. ${ }^{5}$ But we need to supplement error theory with an experience generator.

Fortunately, we already have an explanation of our experiences that is consistent with the falsity of our moral beliefs. Substantial effort has been dedicatedby anti-realists of all stripes, together with empirical psychologists - to showing that our moral intuitions and beliefs can be proximately explained by a myriad of cultural and psychological factors and ultimately explained by evolutionary biology. This evolutionary/cultural/psychological (in short, ECP) story is an experience generator. So our skeptical hypothesis includes both moral error the-

3 Note: moral knowledge, not normative knowledge. The subject here is moral skepticism, not a broader normative skepticism.

4 Sinnott-Armstrong, Moral Skepticisms.

5 Other anti-realist positions in metaethics avoid saying that our moral beliefs are false. Constructivists and relativists hold that our moral beliefs are true-they are just made true by our contingent attitudes or social circumstances. Expressivists either hold that our moral judgments are not truth-valuable, or else that our moral judgments are true in a deflationary sense. 
ory and the ECP story. Call this conjunction of error theory and the ECP story Error-ECP. Thus:

\section{Moral Closure Argument}

1. I do not know that Error-ECP is false.

2. If I know that killing is wrong, then I know that Error-ECP is false.

3. Therefore, I do not know that killing is wrong.

The argument generalizes at least to any agents like us in situations like ours. (Perhaps God can know that Error-ECP is false, but we cannot.) A general skepticism about morality follows. Note that the Moral Closure Argument is not an argument for moral error theory, but instead an argument against the existence of moral knowledge. Error theory is relevant to this argument only because error theory is an essential part of any incompatible skeptical hypothesis relative to positive moral propositions.

The first premise of any closure argument is motivated by the idea of evidential underdetermination. When someone knows that $P$, there is always a way in which they know that $P$. Thus, when someone claims "I know that $P$ is false," a wholly appropriate way to challenge this claim is to ask "How do you know that?" At this point, the purported knower must appeal to some evidence that indicates that $P$ is false-evidence that would rule out the possibility that $P$. But for a skeptical hypothesis, no such evidence is available. Error-ECP entails that our experiences are exactly the same as they are in the actual world. Because of this, none of our experiences gives us any reason to think that Error-ECP is false. And if none of our experiences give us any reason to think that Error-ECP is false, we are not justified in thinking that Error-ECP is false. So we do not know that Error-ECP is false.

That is the logic of the External World Closure Argument as well. The BIV and evil demon hypotheses are hypotheses that entail that your experiences are all exactly the same as they are in the actual world-this is the role of the experience generator. Accordingly, there is (seemingly) no basis on which one might rule out these skeptical hypotheses. So we do not know they are false. The same logic applies to both our inability to rule out Error-ECP and our inability to rule out handless-BIv.

The second premise of the Moral Closure Argument follows from Closure, provided that killing's being wrong entails that error theory is false and that the subject has competently deduced the falsity of error theory from the wrongness of killing. These two provisos will, generally, be satisfied. Killing's being wrong does entail that error theory is false. And while some subjects may not recognize the relation between substantive first-order moral claims like "killing is wrong" 
and moral error theory, this argument is addressed to those who are able to make the relevant deduction (e.g., academic philosophers). And avoiding the skeptical conclusion by claiming ignorance of basic logic seems a desperate gambit. Thus, if we are to resist the second premise of the Moral Closure Argument, we must reject Closure. But Closure is hard to reject-if $P$ entails $Q$ and you know that $P$ is true, and recognize the entailment relation that holds between $P$ and $Q$ and come to believe that $Q$ is true because it is entailed by $P$, why would you not know $Q$ ? Thus: if we knew that killing is wrong, we would be in a position to know that Error-ECP is false.

The Moral Closure Argument highlights the key question that lies at the heart of all skeptical challenges: How do you know you are not wrong? The error theorist's position is dismissed (Killing is not wrong? That cannot be right!) more often than it is argued against. Error theorists are entitled to feel a little frustration. ${ }^{6}$ The Moral Closure Argument turns that frustration into a productive use: a demand that error theory be refuted, lest one cede the ground to the skeptic.

In short: we need to have evidence that Error-ECP is false if we are to be justified in believing that any moral claims are true. But we have no evidence that serves to rule out Error-ECP, since that hypothesis provides an excellent account of all our experiences. That is why we have no moral knowledge.

\subsection{A Defensive Plan}

This marks the end of my positive argument for moral skepticism. My arguments here were brief; closure arguments are well understood. There is no need to belabor the familiar.

What comes next is defense against objections. The objections that I will consider fall into two broad camps. In sections $2-6$, I will examine objections that purport to show that the Moral Closure Argument fails for the same reason that the External World Closure Argument fails (whatever that reason might be). In response, I will show that the most popular strategies for responding to the External World Closure Argument systematically fail if we attempt to apply them to the Moral Closure Argument. Despite the similarities between the two arguments, the Moral Closure Argument is a much stronger argument than the External World Closure Argument because it cannot be answered in the same way. Of course, the External World Closure Argument has been answered in many different ways, and I cannot survey every possible way to adapt a response to the External World Closure Argument as a response to the Moral Closure Argument. So I do not pretend that my arguments here are conclusive. But by examining a wide range of different, promising anti-skeptical strategies and showing the ways

6 Joyce, "Arguments from Moral Disagreement to Moral Skepticism." 
in which they systematically fail to prove useful in answering the Moral Closure Argument, I will show that the Moral Closure Argument is a much more potent skeptical challenge than is typically assumed. It is an argument that anti-skeptics must take seriously.

This discussion will raise to salience a second class of methodological objections, regarding (a) the extent to which the Moral Closure Argument generalizes and (b) whether closure arguments raise independently interesting skeptical concerns. We will consider these objections in sections 7 and 8 .

\section{THE SPECIAL CASE OBJECTION}

The Moral Closure Argument has been considered before, but it has rarely been taken seriously. Sinnott-Armstrong discusses the Moral Closure Argument at some length, but ultimately sets it aside in favor of a discussion of a Regress Argument for moral skepticism. ${ }^{7}$ (According to the Regress Argument, our reasons for our moral beliefs must themselves be justified by prior moral beliefs, which themselves must be justified by prior moral beliefs, and so on ad infinitum.) Sinnott-Armstrong holds that the Moral Closure Argument and the Regress Argument are mutually supporting, but he thinks that the Regress Argument is a more illuminating skeptical challenge than the Moral Closure Argument. ${ }^{8}$ And Sinnott-Armstrong is a skeptic; he is sympathetic to the Moral Closure Argument. Anti-skeptics tend to be more bluntly dismissive of the Moral Closure Argument. For instance, Michael Huemer writes:

We should not consider it a fair move ... for someone arguing against ethical intuitionism to deploy general skeptical arguments... Thus, if some particular argument against intuitionism can be shown to be merely a special case of a more general argument impugning our knowledge of those sorts of things, then I may set that argument aside as not relevant to the current discussion. ${ }^{9}$

Call this the Special Case Objection. According to the Special Case Objection, the Moral Closure Argument is defective because it is just a special case of a

7 Sinnott-Armstrong, Moral Skepticisms, chs. 3-4.

8 Sinnott-Armstrong's defense of the regress assumes that it is a flaw in any epistemic position if that position begs the question against the skeptic. I hold, along with most contemporary epistemologists, that question-begging anti-skeptical arguments may be sound (see section 4 below). So Sinnott-Armstrong's version of the Regress Argument does not convince. I think Sinnott-Armstrong's Regress Argument can be repaired, but exploring how to do this falls outside the scope of this paper.

9 Huemer, Ethical Intuitionism, 12. 
more general closure argument schema. Closure arguments are bad; one of the major lessons of twentieth-century epistemology is that the External World Closure Argument is unsound. Accordingly, we have every reason to be suspicious of the Moral Closure Argument; an argument based on a bad argument is also probably bad. This point has been advanced by many others. ${ }^{10}$

\subsection{Response 1: Validity and Soundness}

There are two basic problems with the Special Case Objection. The first is that it reads too much into structural similarities between distinct arguments. If two arguments are structural analogues, both arguments will be equally valid; if the premises are related to the conclusion in the same way in both arguments, then, if the premises do not entail the conclusion in the first argument, they will not entail the conclusion in the second argument either. But the logical structure of closure arguments is just a modus tollens, and that is a valid argument structure. So the structural similarities between closure arguments give us no grounds for rejecting all such arguments.

If all closure arguments are unsound, then, it must be because these arguments have false premises. So the Special Case Objection would be an apt challenge if the Moral Closure Argument and the External World Closure Argument shared premises. But they do not. The first premise of the Moral Closure Argument concerns Error-ECP, not BIVs or evil demons. A closure argument against moral knowledge that began with the premise "I know I'm not being deceived by a demon" would be just as suspect as the External World Closure Argument. ${ }^{11}$ If this is supposed to be the point behind the Special Case Objection, then it is well taken. But in that case, the Special Case Objection does not apply to the Moral Closure Argument. So there is no general reason to think that the Moral Closure Argument will be unsound if the External World Closure Argument is unsound.

\subsection{Response 2: Sound Closure Arguments}

The second problem with the Special Case Objection is that it implies that all closure arguments are unsound, in light of the fact that the External World Closure Argument is unsound. But this is wrong; there are sound closure arguments.

Consider the claim that there are witches. For much of human history, it seemed to many people as though there were witches. But we have been able to

See, e.g., Shafer-Landau, Moral Realism, 239-40; Star, "Moral Knowledge, Epistemic Externalism, and Intuitionism;" Enoch, Taking Morality Seriously, 157-58; McCann, "Conative Intuitionism;" Kulp, "Moral Facts and the Centrality of Intuitions;" Vavova, "Debunking Evolutionary Debunking;" Rosen, "What Is Normative Necessity?"

May, "Skeptical Hypotheses and Moral Skepticism." 
explain away all of this seeming evidence. Religious hysteria, social pressure to condemn others as witches, and superstitions all contributed (inter alia) to its seeming that there are witches. The claim of the previous sentence is an experience generator. Conjoin that to the negation of the claim that witches exist, and we have an incompatible skeptical hypothesis relative to the claim that witches exist. Call that the No Witch Skeptical Hypothesis. Now consider the following closure argument:

\section{Witch Closure Argument}

1. Reverend Parris does not know that the No Witch Skeptical Hypothesis is false.

2. If Reverend Parris knows that Tituba is a witch, then Parris knows that the No Witch Skeptical Hypothesis is false.

3. Therefore, Parris does not know that Tituba is a witch.

This argument is sound. It is also (potentially) compelling. The Witch Closure Argument directly presents Parris with the possibility of error. It makes salient the key question that lies at the heart of all skeptical challenges: How do you know you are not wrong? This is a question that Parris should ask himself since, indeed, he is wrong; there are no witches. And by supplementing this possibility of error with a cogent experience generator, it becomes clear that Parris really has no grounds to rule out the No Witch Skeptical Hypothesis. If Parris were to claim that the mere possibility of witchless worlds does nothing to cast doubt on his belief that there really are witches (and, besides, all closure arguments are bad arguments!), he would be missing the point. The Witch Closure Argument is exactly the sort of thing that should make Parris doubt the existence of witches.

We are more familiar with unsound closure arguments than we are with sound closure arguments, because the obviously sound closure arguments, like the Witch Closure Argument, usually are not philosophically interesting. This can bias us to think that all closure arguments contain some deep flaw. But that cannot be right. There are things we should be skeptical about, after all, and closure arguments can help motivate an appropriate skepticism by presenting misguided anti-skeptics with the possibility of error in a compelling way. This is what the Moral Closure Argument does.

\section{RELEVANT ALTERNATIVES}

If there is no general reason to think that the Moral Closure Argument is unsound in virtue of being a closure argument, perhaps there is some particular reason to think this. That is, perhaps the flaw that the External World Closure Argument 
manifests - whatever that might be —is also present in the Moral Closure Argument. In the next four sections, I will look at four ways in which this suggestion might be substantiated. The four avenues of response that I will consider here are four of the most popular ways of responding to the External World Closure Argument. Thus, while I cannot evaluate every possible response to the External World Closure Argument, the failures of these four responses will show that the Moral Closure Argument is not so easily answered.

\subsection{Objection: Error-ECP Is Irrelevant}

The first particular objection we will examine comes from the Relevant Alternatives framework. According to the Relevant Alternatives framework, a subject knows that $P$ only if that subject can rule out all of the relevant alternatives to $P$. But not every alternative to $P$ is relevant. If a certain proposition, $Q$ is an irrelevant alternative to $P$, then a subject's inability to rule out $Q$ is no bar to knowing $P$.

This Relevant Alternatives framework forms the core of a popular response to skeptical hypothesis arguments. ${ }^{12}$ All (incompatible) skeptical hypotheses relative to $P$ are alternatives to $P$. But if a skeptical hypothesis is not a relevant alternative, then it matters little if we are unable to rule it out. Anti-skeptics can apply this thought to the Moral Closure Argument. If Error-ECP is an irrelevant alternative, it need not be ruled out, and thus our inability to rule it out is no bar to our possessing moral knowledge.

\subsection{Response: The Modern Scientific Worldview Must Be Relevant}

Schematically, this suggestion is sensible, and familiar. In Sinnott-Armstrong's discussion of the Moral Closure Argument, Sinnott-Armstrong accepts the Relevant Alternatives framework and, accordingly, structures his discussion around the question of whether Error-ECP ("moral nihilism") is relevant. This depends on what it takes for an alternative to be "relevant" at all. Thus, Sinnott-Armstrong looks hard for an acceptable account of relevance. He cannot find one. Accordingly, he adopts a higher-order, "Pyrrhonian" skepticism: we do not know whether we have moral knowledge because we do not know whether Error-ECP is relevant.

I will not defend an account of relevance here because I am agnostic about the Relevant Alternatives framework. But I do not need an account of relevance; if the Relevant Alternatives framework is correct, then no matter how we understand the notion of a "relevant" alternative, Error-ECP is relevant.

Consider that, for any proposition, $P$, there is really only one claim that is an alternative to $P: \sim P$. When Relevant Alternatives theorists talk about different 12 Dretske, "Epistemic Operators." 
alternatives to $P$, they are not talking about propositions other than $\sim P$. They are talking about different ways for $P$ to be false-or, more precisely, different stories about why it might seem that $P$ is true, even though it is false. Thus, if we accept the Relevant Alternatives framework, what we are evaluating for relevance is the experience generators of different skeptical hypotheses. The irrelevant alternatives will be alternatives that appeal to experience generators that are outlandish, to use Sinnott-Armstrong's apt term. The idea that you could be a BIV is an outlandish one, indeed.

Thus, if we are to apply the Relevant Alternatives framework to rule out Error-ECP, it must be on the grounds that the experience generator of Error-ECP is outlandish. But the experience generator of Error-ECP is the ECP story, and that story is not an error theorist's wild conjecture. It does not talk about demons or brains in vats. It is, instead, an empirically verified story, and the consensus view among psychologists who study the origins of our moral beliefs. ${ }^{13}$ This scientifically respectable story is not outlandish in any sense of the word. So Error-ECP must be a relevant alternative to our moral beliefs, if anything is.

One might object that Error-ECP really is an outlandish view. What makes it outlandish is not its commitment to a scientific explanation of our experiences, but the fact that it is a version of error theory. The outlandish feature of Error-ECP is Error, not ECP.

This is an important objection, but it is not based on the Relevant Alternatives framework. The Relevant Alternatives framework provides a way of evaluating the experience generators of skeptical hypotheses. Responses to skepticism that proceed by arguing that it is absurd that our commonsense beliefs might be false are Moorean responses to skepticism. I turn to those next.

\section{MOOREANISM}

Mooreanism is the view that we can know that skeptical hypotheses are false in virtue of the fact that we have basic knowledge that certain of our first-order beliefs are true. A Moorean about the external world says that she can know she is not a BIV because she has basic knowledge that she has hands. A Moorean about morality, by like token, is someone who says that she can know that Error-ECP is false because she has basic knowledge that killing is wrong (for example).

The most common objection to Moorean responses is that they beg the question. In making a claim to basic knowledge that $P$, Moorean responses to skepticism begin by assuming the truth of $P$; this is blatantly question begging, 
and that seems like a bad thing. ${ }^{14}$ Sinnott-Armstrong structures his discussion of moral skepticism around the question of whether any arguments can be advanced that do not beg the question against a moral nihilist. ${ }^{15}$

But it is not obvious that begging the question is bad. Question-begging arguments may be sound, after all. Further, the premises of sound question-begging arguments might be premises that I know to be true, even if my interlocutor does not believe them. So what, then, is the problem with making a question-begging argument, provided that it is valid and that I know the premises to be true? The only problem seems to be that it cannot convince dedicated skeptics to abandon their skepticism. ${ }^{16}$ But, of course, it is impossible to convince people who are dead set against being convinced. So the only flaw in question-begging arguments is that they do not accomplish an impossible task; that does not look like much of a flaw.

This does not mean that the Moorean response is in the clear. Question-begging arguments are fine, provided that the argument is valid and that I know the premises to be true. But how can the anti-skeptic substantiate her claim to knowing the commonsense proposition in question, in light of the skeptical argument? That is the burden the Moorean must shoulder.

One way to substantiate this Moorean strategy is to offer a particularist response to the Problem of the Criterion. The Problem of the Criterion is an ancient methodological puzzle within epistemology—how do we know the extent of our knowledge unless we first have an idea of what knowledge is? And how do we know what knowledge is unless we first have an idea of the kinds of things we are talking about when we are theorizing about knowledge? It seems like we cannot answer either question until we have first answered the other. The particularist grasps the first horn of this dilemma and holds that our knowledge of particular matters of fact is absolutely methodologically prior to our acceptance of any epistemic principles. So particularism provides us with one way to be Mooreans-by holding that claims like "I know that killing is wrong" or "I know I have hands" are methodological fixed points in epistemic theorizing.

I have nothing to say in response to such a Moorean particularist-how could I? Particularists are methodologically committed to not abandoning their claims to knowledge, and as we just observed, there is no convincing people who are dead set against being convinced. Yet it is this very inflexibility of particularism that makes is such an unattractive solution to the Problem of the Criterion. The best response to the Problem of the Criterion seems to me to be a response

14 Joyce, "Arguments from Moral Disagreement to Moral Skepticism."

15 See note 8 above.

16 Pryor, "What's Wrong with Moore's Argument?" 
that denies that either particular claims or general principles have absolute priority over the other. The best epistemic theory is to be found in a state of reflective equilibrium between particulars and principles. This means that it is incumbent upon Mooreans to do more than insist on their commonsense claims. They should give some account of why the claims that they are insisting on are the right claims to insist on.

The simplest way to do this was suggested by Moore himself. According to Moore, we should view skeptical arguments as presenting a kind of aporia, where the truth of the premises and the negation of the conclusion all seem plausible, yet one of those claims must be false. And, in such a situation, the thing to do is to reject the claim in which we have the lowest degree of confidence. Thus, the skeptic can be dismissed on the grounds that "It seems to me more certain that I do know that this is a pencil and that you are conscious, than that a single one of these four assumptions [of the skeptical argument] is true, let alone all four." ${ }^{17}$ "Confidence may serve as defeasible indirect evidence of the truth of a claim." ${ }^{8}$

But it is implausible that mere confidence serves as evidence of any kind in favor of a claim. People can be (and often are) irrationally confident, and irrational confidence in a claim is no evidence for the truth of that claim. How confident an agent ought to be in a claim is a function of what evidence the agent has for that claim, not the other way around. If we were to present Reverend Parris with a modern scientific explanation of all the things that he takes to be evidence that Tituba is a witch and ask him, in light of the availability of this scientific explanation, what reason he has to think that Tituba is a witch, it will not do for Parris to respond by avowing his unwavering confidence. We need evidence of a kind to substantiate the Moorean position, but mere confidence will not do.

\subsection{Moorean Dogmatism}

The most well-developed and influential version of Mooreanism—dogmatismaddresses this problem. Dogmatism was developed by Jim Pryor and Michael Huemer as a response to the External World Closure Argument, and in later work, Huemer expanded his account to address the Moral Closure Argument as well. ${ }^{19}$ This makes Moorean dogmatism a strong candidate for the best response to the Moral Closure Argument. The cornerstone of the dogmatist account is a principle called 
Phenomenal Conservatism (PC): If it seems to $S$ as if $P$, then $S$ has at least prima facie justification for believing that $P .{ }^{20}$

PC contains two important notions. First is the notion of P's seeming true to $S$. Seemings are mental states that have propositional content, thereby presenting the world as being a certain way and (according to PC) justifying our belief that the world is that way. Sensations are perceptual seeming states. Memory and introspection are also seemings, although of different kinds. And there is a fourth kind of seeming, an intellectual seeming state, where some proposition just seems true on reflection. These intellectual seeming states are intuitions. And moral intuitions are just intellectual seeming states whose content is a moral proposition. $^{21}$

According to PC, our sensations (perceptual seeming states) present the external world as being a certain way; consequently, we are prima facie justified in believing the world is that way. In similar fashion, our moral intuitions present certain moral propositions as being true; consequently, we are prima facie justified in believing those propositions. Thus, while our experiences might be the same in both a skeptical scenario and non-skeptical scenario, the content of our experiences uniquely supports the non-skeptical hypothesis, by PC.

To say that one is prima facie justified in believing $P$ is only to say that the agent has a defeasible reason to believe $P$. But undefeated prima facie justification is sufficient for all-things-considered justification. Thus, having a seeming state that $P$ is different from merely being confident that $P$, but an undefeated seeming that $P$ makes it rational to be confident that $P$. If you are prima facie justified in believing that $P$, and there are no defeaters for your belief, then you are all-things-considered justified in believing that $P$. In this way, we may come to know that the commonsense hypothesis is true and so, by Closure, may come to know that the skeptical hypothesis is false.

\subsection{Response: Undermining Prima Facie Justification}

I will grant, arguendo, that $\mathrm{PC}$ is true and that moral intuitions are seeming states with moral contents. From this, it follows that we have some prima facie justified moral beliefs. Both of those premises are controversial, but I will accept them anyway because Huemer makes no case that our moral beliefs are undefeated. And this is how Huemer's argument fails: there are defeaters for our moral beliefs that are not present for our external world beliefs.

So, for Huemer and Pryor, what does it take for prima facie justification to 
be defeated? Before we answer that question, a reminder: in section 1, I distinguished between a compatible and an incompatible skeptical hypothesis, and showed that only incompatible skeptical hypotheses can feature in closure arguments. But Huemer and Pryor dislike closure arguments, and so interest themselves in compatible skeptical hypotheses. When Pryor and Huemer talk about a skeptical hypothesis, they are talking about what I have been calling an experience generator: to wit, an explanation of your experiences that is consistent with the falsity of the proposition in question. Keeping that in mind, here is Pryor on what it would take to defeat prima facie justification:

This prima facie justification can be undermined or threatened if you gain positive empirical evidence that you really are in a skeptical scenario. (For instance, if a ticker tape appears at the bottom of your visual field with the words "You are a brain in a vat...") If you acquire evidence of that sort, then you'd have to find some non-question-begging way of ruling the skeptical hypothesis out, before you'd be all things considered justified in believing that things are as your experiences present them. In the standard case, though, when the prima facie justification you get from your experiences is not defeated or undermined, then it counts as all things considered justification, without your having to do this. ${ }^{22}$

Huemer agrees, saying: "Does the brain-in-a-vat hypothesis, itself, constitute such a defeater? It would, if I had some reason for accepting it - that is, if I had significant evidence that I am a brain in a vat. But I have no such evidence, nor have the world's skeptics proven interested in trying to provide that sort of evidence."23

Pryor and Huemer both provide one example of what would defeat prima facie justification: evidence in favor of a (compatible) skeptical hypothesis, or what I have been calling an experience generator. And this seems right. If you learn that you are dreaming, that undermines your perceptual justification for thinking that you have hands, even though the dreaming hypothesis is compatible with your having hands. So Pryor and Huemer's Moorean account rests on the claim that we have no evidence in favor of an experience generator (like the BIV hypothesis) that would undermine our justification for thinking that we have hands. A ticker running across the bottom of our visual field telling us that we are brains in vats (indeed, any ticker running across the bottom of our visual field) would be hard to account for on the hypothesis that our senses put us

22 Pryor, "The Skeptic and the Dogmatist," 537-38. Pryor reiterates this suggestion in "What's Wrong with Moore's Argument?"

23 Huemer, Skepticism and the Veil of Perception, 183. 
in contact with an external world. Accordingly, experiences like that would be good (if not conclusive) evidence that some skeptical hypothesis is true. Fortunately, we have no evidence like that.

But we cannot say the same thing about the moral case. Our prima facie justified moral beliefs are defeated if we have "positive empirical evidence" in favor of an experience generator of a skeptical hypothesis relative to our moral beliefs. And we do have evidence like this! The experience generator for the Moral Skeptical Hypothesis is the ECP story, and that story is supported by copious empirical research. Thus, there is a defeater for the prima facie justification provided by our moral intuitions.

I am not arguing here that evidence for an experience generator is generally a defeater for any of our beliefs. (I do think that is true, but I argue for it elsewhere. $)^{24}$ Rather, the point is that Pryor/Huemer-style dogmatism cannot be used to substantiate a Moorean response to the Moral Closure Argument. Pryor's and Huemer's version of Mooreanism rests on a principle of prima facie justification that contains a proviso which states conditions under which justification will be defeated. As Pryor and Huemer both correctly point out, that proviso is unsatisfied in the case of our external world knowledge: we have no reason to think that any experience generator relative to our beliefs about the external world is true. However, we do have reason to think that the experience generator of Error-ECP is true. So the proviso is satisfied in the case of the Moral Closure Argument. The dogmatist response fails.

\section{INFERENCE TO THE BEST EXPLANATION}

Another popular response to the External World Closure Argument appeals to Inference to the Best Explanation (IBE). According to this response, the hypothesis that there is an external world that is largely the way that we perceive it to be is the best explanation of our experiences (particularly, our sensory experiences). ${ }^{25}$ Thus, by IBE, we can know that the anti-skeptical hypothesis is true and that the skeptical hypothesis is false.

A similar argument can be given against the Moral Closure Argument. According to some moral realists (most notably the "Cornell realists"), moral facts can explain other kinds of facts-including, potentially, facts about our expe-

24 Lutz, "What Makes Evolution a Defeater?"

25 Cf. Russell, The Problems of Philosophy, ch. 2; Vogel, "Cartesian Skepticism and Inference to the Best Explanation." This is, incidentally, the response to the External World Closure Argument to which I am most sympathetic. 
riences. And if moral facts can explain our experiences, it is possible for moral facts to constitute the best explanation of our experiences.

This position has been developed by Majors in response to Sinnott-Armstrong's Regress Argument. ${ }^{26}$ Sinnott-Armstrong argues that moral facts do not feature in the best explanation of anything: our best explanations will appeal only to nonmoral base properties, not to moral properties. ${ }^{27}$ Majors responds by saying that moral properties are a kind of higher-order, supervenient natural property. ${ }^{28}$ These higher-order properties are individuated by their distinct explanatory profile. If we want to know why a revolution occurred, we might explain this occurrence by giving a detailed description of the complete political and social circumstances just prior to the revolution; but the best explanation of that revolution is the higher-order property that these political and social circumstances constitute injustice. This higher-order explanation is the most accurate, informative explanation of the revolution, because it is the explanation that captures the appropriate degree of generality - revolutions are far more likely to occur in political and social conditions that manifest injustice than in those that do not. ${ }^{29}$

Thus, Majors argues that because higher-order properties have robust explanatory power at the right level of generality, IBE will give us a reason to believe in these higher-order moral properties and reject Sinnott-Armstrong's account of explanations in terms of nonmoral base properties. ${ }^{30}$ By IBE, we can know that killing is wrong, and thus, by Closure, come to know that Error-ECP is false. The Moral Closure Argument fails.

\subsection{Response: Higher-Order Nonmoral Properties}

This debate between Sinnott-Armstrong and Majors is confused. Sinnott-Armstrong's position is that nonmoral base properties can do all the explanatory work; Majors's counter is that higher-order moral properties are needed to do explanatory work. But even if Majors is correct to say that we need to refer to higher-order properties to capture the right level of generality in our explanations - and I do find this position compelling - then this only shows that we must have higher-order properties in our explanations. It does not show that those higher-order properties must be moral properties.

Error-ECP is not a view that denies the existence of higher-order properties

26 Majors, "Moral Explanation."

27 Following Harman, The Nature of Morality.

28 Following Sturgeon, "Moral Explanations."

29 Railton, "Moral Realism."

30 See also Oddie, Value, Reality, and Desire. 
with explanatory power. Many of the properties that feature in the ECP story are higher-order properties of the kind that Majors is interested in. So the relevant comparison between explanations, for our purposes, is a comparison between a view on which there are higher-order moral properties with explanatory power, and a view on which there are higher-order properties with explanatory power that are not moral. It is easy to miss this distinction because many of the concepts that we use to pick out such higher-order properties are "thick" normative concepts-INJUSTICE is a perfect example. Thick concepts like INJUSTICE have both normative and descriptive significance. But these normative and descriptive aspects of the concepts are conceptually separable. Let us call the descriptive aspect of the concept of injustice DESCRIPTIVE-INJUSTICE, and the property that is picked out by this concept descriptive-injustice. According to Error-ECP, there is a nonmoral property of descriptive-injustice that (inter alia) explains why political revolutions tend to happen in societies that have this property, and tend not to happen in societies that lack it.

For comparison, consider ethnic slurs. Some bigots have the concept of a MICK, but we can pick out the descriptive aspect of this concept-PERSON FROM IRELAND - which refers to the nonnormative property of being from Ireland. The property of being from Ireland has explanatory power (e.g., it explains the accent). But the fact that this property has explanatory power gives us no reason to believe in the normatively valenced property of being a rotten mick. Similarly, some social organizations - the descriptively-unjust ones — might tend toward political revolution. But the explanatory power of descriptive-injustice gives us no reason to believe in a normatively valenced property of injustice.

If the anti-skeptic seeks to use IBE to rule out Error-ECP, that means that we need to ask whether a normatively valenced property of injustice explains our observations of patterns in political revolutions better than explanations couched entirely in terms of descriptive-injustice. Thus, the only way to use IBE to argue against Error-ECP is to argue not just that there are higher-order properties with robust causal profiles that can explain events like political revolutions, but also that those properties have a moral valence, and that this moral valence adds to their explanatory power. But we have no reason to accept these further claims. The fact that we should believe in higher-order properties is no evidence that we should believe in moral properties.

\subsection{The Epistemic Quality of Error-ECP}

The arguments of the last three sections have a common theme. In assessing whether an alternative is "relevant" or not, we need to look to the experience generator of the skeptical hypothesis in question. Because the experience gener- 
ator of Error-ECP is a scientifically confirmed account, rather than an outlandish conjecture about demons or brains in vats, the Relevant Alternatives response fails. Moorean accounts of justification only succeed in providing all-things-considered justification if we have no evidence in favor of an experience generator of a skeptical hypothesis. But when the skeptical hypothesis in question is Error-ECP (rather than handless-BIv), we do have evidence for the experience generator. And IBE is no help in answering the Moral Closure Argument because the experience generator of the Moral Closure Argument is, as a scientifically confirmed theory, a product of reasoning in accordance with IBE.

The point is not that evidence in favor of the ECP story is a reason to believe that there are no moral facts. As I argued in section 1, the intuitive force of the Moral Closure Argument rests on the fact that the anti-skeptic has no good answer to the question "How do you know you are not wrong?" Yet the most prominent answers to the External World Closure Argument all, in one way or another, indicate how strange and implausible it is to suggest that we are dupes of an evil demon or brains in vats. But to apply these same counterarguments to the Moral Closure Argument, the anti-skeptic will have to argue that it is strange and implausible to suggest that our beliefs are the product of the ECP story. But that is not implausible at all.

This is similar to a point raised by McPherson. ${ }^{31}$ McPherson (who is neither an error theorist nor a skeptic) argues that Moorean responses cannot rule out moral error theory. Moorean responses only serve to rule out a skeptical hypothesis if that skeptical hypothesis lacks "generic indicators of epistemic quality."32 And, McPherson argues, moral error theory does not lack generic indicators of epistemic quality. McPherson's account of the generic indicators of epistemic quality is different from my own, and he does not appreciate the importance of the distinction between falsity stipulations and experience generators within an incompatible skeptical hypothesis. But his anti-Moorean argument is essentially correct.

At this point, one is liable to have a number of worries about how far this skeptical argument generalizes and how it relates to other kinds of skeptical arguments, particularly evolutionary debunking arguments. I address these concerns in sections 7-8. For now, there is one more important response to the Moral Closure Argument to examine. 


\section{EXTERNALISM}

We are currently examining popular ways of responding to the External World Closure Argument, and seeing whether they can be adapted to serve as responses to the Moral Closure Argument. In the previous two sections, we looked at internalist responses to skepticism, which ground justification in either the content of, or the best explanation of, our experiences. In this section, we will look at externalist responses to skepticism, which hold that we are justified in rejecting error theory in virtue of things external to our experiences.

The externalist offers a simple and compelling thought: because a good experience generator will provide an adequate explanation of all of our experiences, we have no internally accessible grounds for ruling out skeptical hypotheses. Yet we clearly do know things; it follows, then, that our beliefs are justified in virtue of facts that are not internally accessible to us. If we are being deceived, then our beliefs are not justified. But if we are not being deceived, then our moral beliefs are justified (e.g., in virtue of our reliability). This thought can be applied in the domain of morality just as easily as in other domains. If we have no internally accessible basis for ruling out Error-ECP, but are nonetheless justified in holding moral beliefs (and of course we are justified in holding moral beliefs!), then we must be justified in holding those beliefs on external grounds. ${ }^{33}$

\subsection{Response: The New Evil Demon Problem}

The main problem with externalist responses to skepticism is that they incorrectly predict that we have different evidence depending on whether or not we are being deceived. That commitment is the core of the externalist anti-skeptical project. But it is counterintuitive, as the (rightly) famous New Evil Demon Problem shows. ${ }^{34}$ If two agents have all the same experiences and background beliefs, those two agents will be justified in believing all the same things, regardless of whether they are forming true beliefs or not. Someone who is being deceived by an evil demon, but does not know it, is just as justified in their beliefs as someone who is not being deceived at all. Provided that the demon's illusion is sufficiently comprehensive, it would be irrational for the deceived individual to do anything other than believe in accordance with the demon's illusion. So while the epistemic externalist claims that we are justified in believing fewer things in cases where we are deceived, that just seems wrong.

Star holds that epistemic internalism lacks the resources to overcome moral 
skepticism, and thus we must be externalists or else accept moral skepticism. ${ }^{35}$ Star takes this to be conclusive reason to be an epistemic externalist. I agree that our inability to provide an internal justification of our moral beliefs forces us to choose between either externalism or moral skepticism. However, in light of the New Evil Demon Problem, moral skepticism seems to be the correct conclusion to draw.

\subsection{Evidence and Experience}

The New Evil Demon Problem presents us with an intuitive datum: that our evidence, and thus our justification, is the same whether or not we are being deceived (provided the deception is sufficiently comprehensive). Externalists have responded to this challenge in two different ways. According to what we may call the concessive response, our beliefs in an external world are equally rational whether or not we are deceived, but only in cases where we are not deceived are our beliefs fully justified. ${ }^{36}$ Concessive externalists are correct to say that there are epistemic goods (like, perhaps, reliability) that are not internally accessible to us. But in conceding that it is not rational to believe that one is being deceived in cases of sufficiently comprehensive deception, a concessive externalist is conceding that our experiences are not sufficient to rule out the skeptical hypothesis. That is enough to get a closure argument off the ground.

A second externalist response, which we may call the knowledge first response, comes from Timothy Williamson. ${ }^{37}$ Williamson holds that the only true epistemic good is knowledge, and that our evidence consists in our knowledge; his slogan is " $E=K$." If $E=K$, then, because we have knowledge in the "good case" (where we are not being deceived) and lack knowledge in the "bad case" (where we are being deceived), we have different evidence in those two cases. This provides a potential answer to the Moral Closure Argument with a Moorean flavor: because we know many moral facts, those known moral facts serve as evidence that rules out Error-ECP.

Williamson attacks the idea that our evidence consists in our experiences in two ways. First, he presents an argument "on behalf of the skeptic" that purports to prove that our evidence is the same in the good case as in the bad case. He then shows that this argument fails. ${ }^{38}$ Williamson's refutation of his own argument is compelling, but it does not address the New Evil Demon Problem. The New Evil Demon Problem is not supposed to prove that evidence is experience.

Star, "Moral Knowledge, Epistemic Externalism, and Intuitionism."

36 See Bonjour and Sosa, Epistemic Justification, 162-65.

37 Williamson, Knowledge and Its Limits.

38 Williamson, Knowledge and Its Limits, ch. 8. 
It is a burden-shifting argument, intended to show how counterintuitive the externalist account of evidence is. Williamson owes us more.

This comes in the form of a positive argument for $E=K$. However, this argument is weak. One of the premises in Williamson's argument for $E=K$ is that all evidence is propositional. Williamson supports this by arguing that explanatory reasoning is a paradigmatic way by which beliefs can be justified, and only propositions can be the relata of explanations. It makes no sense to demand explanations of objects. ${ }^{39}$ But Williamson is wrong to assume that objects and propositions are the only two things that we might be attempting to explain when we engage in explanatory reasoning. When we engage in explanatory reasoning, we are (often) reasoning about the best explanation of events_-including events that consist in our having experiences. ${ }^{40}$ For instance, my feeling warm (viz., an event of my having a certain warm experience) is best explained by the room being warm, and thus this experience is evidence that the room is warm. Indeed, contra Williamson, it is not clear what would explain an abstract entity like a proposition. For Williamson, propositions are sets of possible worlds; what does it mean for something to explain a set of possible worlds? I have a warm experience if and only if the proposition $<\mathrm{I}$ have a warm experience $>$ is true. But it is not the proposition that is explained, but the event of my feeling warm. ${ }^{41}$

Williamson also argues that we should reject non-propositional evidence because "it is hard to explain how non-propositional evidence contributes to updating probabilities." ${ }^{42}$ But this, too, fails to convince. First, those who endorse evidence-as-experience have put substantial effort into explaining how non-propositional evidence can contribute to updating probabilities. ${ }^{43}$ Second, Williamson's own account of how propositions contribute to updating depends on his assumption that propositions are sets of possible worlds; but this is a controversial assumption. ${ }^{44}$ Third, it is not at all clear that evidential support should be analyzed in terms of "updating probabilities." 45 And fourth, Williamson's objection threatens to confuse the map with the territory: even if it is a necessary condition on a notion of evidence that we must be able to model it probabilisti-

Conee and Feldman, "Replies."

McCain, Evidentialism and Epistemic Justification, 14-15.

Williamson, "Knowledge First," 9.

Dougherty and Rysiew, "Experience First”; Poston, Reason and Explanation.

For a number of arguments against the view that propositions are sets of possible worlds, as well as arguments in favor of rival conceptions of propositions, see King, Soames, and Speaks, New Thinking about Propositions.

Cf. Horgan, “Troubles for Bayesian Formal Epistemology.” 
cally, the fact that propositions serve as inputs in a probability calculus does not prove that evidence consists in propositions, but only that we should be able to model a correspondence between evidence and propositions.

In sum: the New Evil Demon Problem remains a strong reason to reject externalist accounts of evidence and rationality. Williamson's argument for $E=K$ is weak; it provides no good reason to reject the intuitive idea that our evidence consists in our experiences. Thus, externalism is not a promising way to respond to any closure argument, including the Moral Closure Argument.

\section{OVERGENERATING SKEPTICISM}

I have argued in the last four sections that the Moral Closure Argument is compelling because the standard responses to the External World Closure Argument do not apply to the Moral Closure Argument, and thus do not rebut moral skepticism. But one might worry that my arguments threaten to prove too much. One of my main points has been that the skeptical hypothesis that features in the Moral Closure Argument has an experience generator that is an empirically confirmed product of the modern scientific worldview. But this line of argument threatens to overgenerate skeptical conclusions along two different lines: it seems to support skepticism about macrophysical objects, and skepticism about the future. In this section, I will show how closure arguments for skepticism about macrophysical objects and about the future can be answered in ways that do not impute the soundness of the Moral Closure Argument.

\subsection{Objection: Skepticism about Ordinary Objects}

Let us formulate an incompatible skeptical hypothesis relative to the proposition that there are tables, in accordance with the procedure outlined in section 1. First, we stipulate that there are no tables. This, by itself, is not a skeptical hypothesis; we need an experience generator. Unfortunately, we can find one in the modern scientific worldview. The modern scientific worldview tells us that our experiences can be explained in terms of fundamental particles arranged tablewise. But it is logically possible that there can be fundamental particles without there being tables. So a hypothesis according to which there are fundamental particles but no tables-i.e., eliminativism about ordinary objects—is a skeptical hypothesis relative to the claim that there are tables. We have no way to rule that out. So we do not know that there are tables. Call this the Ordinary Objects Closure Argument.

The fact that we are talking about particles arranged tablewise means that we are talking about a property with substantial explanatory power at the right level 
of generality to explain our observations of and judgments about tables. Claiming that those particles-arranged-tablewise are tables adds nothing to the explanatory power of that hypothesis. So IBE gives us no reason to prefer the Arranged Particle Hypothesis to the hypothesis that there are ordinary objects. This is an application of my response to Majors from section 5. Thus, if my arguments there were successful, then it seems a similar strategy can be used to defend the Ordinary Objects Closure Argument. That seems bad.

\subsection{Response: Analyticity}

But we do know that eliminativism about ordinary objects is false, because that hypothesis is conceptually incoherent. It is analytic that, if there are particles arranged tablewise, then there are tables. ${ }^{46}$ According to Thomasson, the relation between our concept of a TABLE and our concept of PARTICLES ARRANGED TABLEWISE is an analytic relation par excellence - the predicate "table" is literally contained in the predicate "particles arranged tablewise." So it is conceptually impossible for there to be particles arranged tablewise without there being tables. Accordingly, any conceptually competent individual can know that the eliminativist hypothesis is false by reflecting on the constituent concepts. ${ }^{47} \mathrm{I}$ find this argument compelling.

But this same response is not available to anti-skeptics about morality. Error-ECP is not conceptually incoherent. Our concepts of natural properties do not contain the concepts of moral properties. To conceive of the world as containing particles arranged tablewise is, ipso facto, to conceive of the world as containing tables. But to conceive of the world as containing killings is not, ipso facto, to conceive of the world as containing immoral actions. This is one important lesson from Moore's Open Question Argument. ${ }^{48}$ " $X$ is particles arranged tablewise, but is $X$ a table?" is a closed question-to ask it betrays a lack of conceptual competence with "particles arranged tablewise." But " $X$ is a killing, but is $X$ wrong?" is not a closed question - to ask it betrays no lack of conceptual competence with "killing."

One might reject Thomasson's account of our concepts and ordinary objects - and her account is controversial. ${ }^{49} \mathrm{~A}$ full defense of Thomasson falls outside the scope of this paper. But if Thomasson's argument fails, skepticism about ordinary objects begins to look much more attractive (to me, at least). ${ }^{50}$ So ei-

46 Thomasson, Ordinary Objects and Ontology Made Easy, ch. 3.

47 Thomasson, Ontology Made Easy.

48 Moore, Principia Ethica; cf. Bedke, "Against Normative Naturalism."

Cf. Button, "Deflationary Metaphysics and Ordinary Language."

See also McPherson, “Moorean Arguments and Moral Revisionism," sec. 3. 
ther Thomasson's argument succeeds, or the Ordinary Objects Closure Argument is sound. Either way, the Moral Closure Argument does not overgenerate skepticism.

\subsection{Objection: Future Outlandishness}

Let us formulate a skeptical hypothesis relative to some claim about the future: say that, in 2050, the Rocky Mountains will spontaneously transform into a giant whale. ${ }^{51}$ This entails that my belief that the Rocky Mountains will undergo no such transformation several decades hence is false. That is not, by itself, a skeptical hypothesis relative to my future belief; we need an experience generator. Unfortunately, we can find one in the modern scientific worldview. Take whatever explanation of my experiences that modern science has to offer; it is logically possible that this explanation is true and for the Rocky Mountains to transform into a giant whale. That is because this experience generator is cashed out in terms of past facts, which is consistent with the claim that the Rockies will become a giant whale in the future. So this Giant Whale Skeptical Hypothesis is a skeptical hypothesis relative to a future belief. We have no way to rule that out. So we do not know that the Rockies will fail to transform into a giant whale. Call this the Giant Whale Closure Argument. This argument will generalize to entail a skeptical conclusion about all future facts, because the past explanation of my experiences will always be consistent with the falsity of my future beliefs. If my strategy in defending the Moral Closure Argument has been successful, then it seems a similar strategy can be used to defend the Giant Whale Closure Argument. That seems bad.

\subsection{Response: Induction}

But we can know that the Giant Whale Skeptical Hypothesis is false by inductive reasoning. The Rocky Mountains have not spontaneously transformed into a giant whale at any point in the past; indeed, nothing has ever spontaneously transformed into a giant whale at any point in the past. And we know why this should be the case, as our best physics gives us an excellent understanding of the ways in which matter changes over time. This long history of mountains not transforming into whales, combined with our understanding of the causal processes that explain this history, give us an excellent inductive basis from which we might infer that the Giant Whale Skeptical Hypothesis is false.

But this same response is not available to anti-skeptics about morality. Inductive reasoning works by extending a pattern of observed facts into unobserved instances. To have moral knowledge by induction, we must first have non-in-

51 I owe this amusing hypothesis, and the accompanying objection, to an anonymous referee. 
ductive moral knowledge. If my arguments thus far have been successful, that is precisely what we lack.

One might worry that Hume's argument for inductive skepticism will create difficulties for this response. Of course the best explanation of our experiences entails that mountains do not transform into whales, but this is only true in the past. But what reason do we have to think that the future will resemble the past? If we think of the Giant Whale Skeptical Hypothesis as an instance of counter-inductive reasoning, then it is question begging to say that we can rule out that hypothesis by inductive reasoning.

This is an important objection, but it can be answered; we can justify induction inductively. Inductive justifications of induction are question begging, but it is no vice for anti-skeptical arguments to beg the question (section 4$){ }^{52}$

One might also worry that I am making things too easy for myself by focusing on the Giant Whale Skeptical Hypothesis. It is, perhaps, reasonable to inductively reject that skeptical hypothesis, but we might have less ground to rule out skeptical hypotheses about the future that are less outlandish. Thus, my arguments here still may direct us toward skepticism about many other future facts. This charge has merit, but it is not an objection. Predictions are hard, especially about the future. I can know that the sun will rise tomorrow and that mountains will not spontaneously transform into whales. About many other things, it is best to suspend judgment.

\section{MAY'S OBJECTION}

When the Moral Closure Argument is discussed in the literature on moral epistemology, it is often dismissed with the Special Case Objection. But Jonathan May has provided a subtler critique of the Moral Closure Argument. ${ }^{53} \mathrm{I}$ turn to this last.

May's concern begins from the observation that the first premise of a closure argument - that we do not know the skeptical hypothesis to be false-is always the most contentious. Once we have established the first premise of the closure argument, the conclusion follows pretty easily. This means that the real force of a closure argument comes from the considerations advanced in favor of the

Inductive justifications of induction are controversial, of course, but pursuing this controversy in depth will take us too far afield. For defenses of an inductive justification of induction, see Alston, "Epistemic Circularity," and Van Cleve, "Reliability, Justification, and the Problem of Induction." I argue in favor of an inductive justification of induction in other work (Lutz, "Defusing the Counterinduction Parody").

May, "Skeptical Hypotheses and Moral Skepticism." 
first premise of the argument. May claims that this is a sufficient reason to set the closure argument aside-discussions of Closure and skeptical hypotheses are a distraction from the core concern, which is the motivation behind the first premise. And what is the motivation behind the first premise? That depends on what the first premise of the Moral Closure Argument is. May argues that if the moral skeptic appeals to hypotheses about brains in vats or evil demons or the like, then the Special Case Objection seems to apply (section 2.1 above). But if the first premise of the Moral Closure Argument is Error-ECP, then the force behind the Moral Closure Argument comes from the fact that we can give evolutionary explanations of our experiences. And this means that the Moral Closure Argument is nothing more than an evolutionary debunking argument, on which there is already a vast literature. The Moral Closure Argument adds nothing new.

This kind of worry may seem to be particularly pressing against the version of the Moral Closure Argument I have defended here. In sections 3-5, I emphasized that Error-ECP is a realistic and not-at-all-outlandish hypothesis because it is a hypothesis that is supported by the available evidence, giving it a high degree of epistemic quality. So if my argument here is successful, it seems to be because we have evidence that our moral beliefs are the product of evolution. This, argues May, makes it a kind of evolutionary debunking argument.

\subsection{Not Quite Debunking}

There are two ways to understand the force behind May's objection. The first is that the evolutionary debunking argument serves as a lemma within the Moral Closure Argument, as it provides the justification for its first premise. Thus, the skeptical force of the Moral Closure Argument would be parasitic on the success of a debunking argument; the closure argument structure adds nothing. This is May's stated concern.

However, the first premise of the Moral Closure Argument is motivated not by a debunking argument but by the idea that we have no evidence against the error theorist's total worldview (error theory plus whatever the best of natural science has to tell us about the origins of our moral beliefs). As Vavova argues, there is a difference between evolutionary debunking arguments, which attempt to show that evolutionary explanations of our moral beliefs give us a good reason to think that our moral beliefs are (probably) false, and the Moral Closure Argument, which attempts to show that our experiences give us no reason to think that our moral beliefs are true. ${ }^{54}$ The central thought behind evolutionary debunking

54 Vavova, “Debunking Evolutionary Debunking." In Vavova's terminology, the former argument is based on the principle GOOD, and the latter argument is based on the principle NO GOOD. 
arguments is that evolution is an "off-track" influence, which would make it a coincidence if our beliefs were true. The Moral Closure Argument, on the other hand, is concerned not with coincidental truth or off-track influences, but with evidential underdetermination..$^{55}$

Furthermore, we can see that the Moral Closure Argument avoids the flaws in existing debunking arguments. According to the debunking argument advanced by Street, our moral beliefs are the product of influences that do not track the moral facts. Vavova argues in response that we have no good reason to think that these influences are "off-track" unless we have moral knowledge. ${ }^{56}$ Without moral knowledge, says Vavova, we have no way of knowing what the moral facts are, and thus no way of knowing whether evolutionary influences are off-track or ontrack. Since the Moral Closure Argument does not concern off-track influences, Vavova's criticisms do not affect the Moral Closure Argument. Enoch criticizes Street's debunking argument by arguing that it is no coincidence that our moral beliefs are true, because we can provide satisfying "third-factor" explanations of the reliability of our moral beliefs. ${ }^{57}$ But again, because the Moral Closure Argument does not concern notions of coincidence or unexplainable reliability, Enoch's response to Street's debunking argument is a non sequitur from the perspective of the Moral Closure Argument.

Enoch and Vavova realize this; they both distinguish between evolutionary debunking arguments and closure arguments based on evidential underdetermination. Against evolutionary debunking arguments, they discuss knowledge of off-track influences and third-factor explanations. But against the Moral Closure Argument, they offer only the Special Case Objection. We have seen why the Special Case Objection fails.

\subsection{But in the Vicinity of Debunking}

One might worry that this defense against May's objection is superficial. Not all debunking arguments appeal to the idea of coincidence, and not all debunking arguments are equally vulnerable to Vavova's or Enoch's objections. Thus, while debunking arguments typically appeal to a different array of epistemic concepts and principles than the Moral Closure Argument, one might suspect that the Moral Closure Argument is, on some level, an attempt to articulate the same thought that skeptics have been attempting to articulate by advancing evolutionary debunking arguments: that the availability of naturalistic explanations of our experiences supports moral skepticism.

55 Street, "A Darwinian Dilemma for Realist Theories of Value."

56 Vavova, "Debunking Evolutionary Debunking."

57 Enoch, Taking Morality Seriously. 
If this is how we are to understand May's objection, then the charge has much more merit. The Moral Closure Argument is within a cluster of skeptical arguments influenced by Harman's famous discussion of moral observation and explanation. ${ }^{58}$ Many different skeptical arguments are a part of this cluster. Arguments from disagreement argue that the best explanation of disagreement is that our moral beliefs are the product of cultural conditioning. ${ }^{59}$ Evolutionary debunking arguments attempt to show that off-track evolutionary influences are the best explanation of our moral attitudes. ${ }^{60}$ Parsimony arguments attempt to show that explanations that do not include moral facts are best in virtue of being simplest. ${ }^{61}$ There is a strong family resemblance between all of these arguments. ${ }^{62}$ All have something to do with the fact that we do not seem to need to include moral facts in the best explanations of our experiences. The fact that Error-ECP gives such a good explanation of our experiences is an essential aspect of the Moral Closure Argument. That puts the Moral Closure Argument squarely within this family of skeptical arguments.

But this is no objection to the Moral Closure Argument. While this family of skeptical concerns is familiar, every way of articulating the challenge thus far has been met with responses that anti-skeptics have, for the most part, been satisfied with. ${ }^{63}$ Yet as I have been arguing here, the standard responses to the Moral Closure Argument are very weak. This makes the Moral Closure Argument a particularly potent member of this family of skeptical arguments, as we have yet to find a compelling response to it.

\section{CONCLUSION}

While the Moral Closure Argument could be viewed as a version of a number of familiar challenges, it constitutes a fruitful perspective on these challenges because it avoids the most substantial objections to other closure arguments (sections 3-6), and to evolutionary debunking arguments (section 8), without overgenerating skeptical results (section 7 ). There may still be effective ways to respond to the Moral Closure Argument. But if there are, they have not yet been

58 Harman, The Nature of Morality.

59 Mackie, Ethics, ch. 1; Wedgwood, "The Moral Evil Demons."

60 Street, "A Darwinian Dilemma for Realist Theories of Value."

61 Harman, The Nature of Morality.

62 Machuca, "Moral Skepticism."

63 Joyce, "Arguments from Moral Disagreement to Moral Skepticism." 
identified. That is why the Moral Closure Argument deserves to be taken seriously by anti-skeptics.

Wuhan University mattlutz326@gmail.com

\section{REFERENCES}

Alston, William P. "Epistemic Circularity." Philosophy and Phenomenological Research 47, no. 1 (September 1986): 1-30.

Bedke, Matthew. "Against Normative Naturalism." Australasian Journal of Philosophy 90, no. 1 (2012): 111-29.

BonJour, Laurence, and Ernest Sosa. Epistemic Justification: Internalism vs. Externalism, Foundations vs. Virtues. Maldwell, MA: Blackwell Publishing, 2003.

Button, Tim. "Deflationary Metaphysics and Ordinary Language." Synthese 197, no. 1 (January 2020): 33-57.

Cohen, Stewart. "Justification and Truth." Philosophical Studies 46, no. 3 (November 1984): 279-95.

Conee, Earl, and Richard Feldman. "Replies." In Evidentialism and Its Discontents, edited by Trent Dougherty, 283-323. Oxford: Oxford University Press, 2011.

Dougherty, Trent, and Patrick Rysiew. "Experience First." In Steup, Turri, and Sosa, Contemporary Debates in Epistemology, 17-21.

Dretske, Fred. "Epistemic Operators." Journal of Philosophy 67, no. 24 (December 1970): 1007-23.

Enoch, David. Taking Morality Seriously: A Defense of Robust Realism. Oxford: Oxford University Press, 2011.

Harman, Gilbert. The Nature of Morality: An Introduction to Ethics. Oxford: Oxford University Press, 1977.

Hawthorne, John. "The Case for Closure." In Steup, Turri, and Sosa, Contemporary Debates in Epistemology, 40-55.

Horgan, Terry. “Troubles for Bayesian Formal Epistemology.” Res Philosophica 94, no. 2 (April 2017): 233-55.

Huemer, Michael. Ethical Intuitionism. Houndmills, uk: Palgrave Macmillan, 2005 .

- Skepticism and the Veil of Perception. London: Rowman and Littlefield, 2001.

Joyce, Richard. "Arguments from Moral Disagreement to Moral Skepticism." 
In Moral Skepticism: New Essays, edited by Diego E. Machuca, 141-62. New York: Routledge, 2018.

- The Evolution of Morality. Cambridge, MA: MIT Press, 2007.

. "The Skeptick's Tale." Philosophy and Phenomenological Research 78, no. 1 (January 2009): 213-21.

King, Jeffrey C., Scott Soames, and Jeff Speaks. New Thinking about Propositions. Oxford: Oxford University Press, 2014.

Kulp, Christopher. "Moral Facts and the Centrality of Intuitions." In The New Intuitionism, edited by Jill Graper Hernandez, 48-66. London: Continuum International, 2011.

Lutz, Matt. "Defusing the Counterinduction Parody." Philosophia 46, no. 2 (June 2018): $379-85$.

—. "What Makes Evolution a Defeater?" Erkenntinis 83, no. 6 (December 2018): 1105-26.

Machuca, Diego E. "Moral Skepticism: An Introduction and Overview." In Moral Skepticism: New Essays, edited by Diego E. Machuca, 1-2. New York: Routledge, 2018.

Mackie, John. Ethics: Inventing Right and Wrong. London: Penguin UK, 1977.

Majors, Brad. "Moral Explanation.” Philosophy Compass 2, no. 1 (January 2007): $1-15$.

May, Jonathan. "Skeptical Hypotheses and Moral Skepticism." Canadian Journal of Philosophy 43, no. 3 (2013): 341-59.

McCain, Kevin. Evidentialism and Epistemic Justification. Abingdon, UK: Routledge, 2014.

McCann, Hugh. "Conative Intuitionism." In The New Intuitionism, edited by Jill Graper Hernandez, 29-47. London: Continuum International, 2011.

McPherson, Tristram. "Moorean Arguments and Moral Revisionism." Journal of Ethics and Social Philosophy 3, no. 2 (June 2009): 1-25.

Moore, G. E. Principia Ethica. New York: Dover Publications, 1903.

Oddie, Graham. Value, Reality, and Desire. Oxford: Oxford University Press, 2005.

Poston, Ted. Reason and Explanation. New York: Palgrave Macmillan, 2014.

Pryor, James. “The Skeptic and the Dogmatist.” Noûs 34, no. 4 (December 2000): $517-49$.

- "What's Wrong with Moore's Argument?" Philosophical Issues 14, no. 1 (October 2004): 349-78.

Railton, Peter. "Moral Realism.” Philosophical Review 95, no. 2 (April 1986): 163207.

Rosen, Gideon. “What Is Normative Necessity?” In Metaphysics, Meaning, and 
Modality: Themes from Kit Fine, edited by Mircea Dumitru, 205-33. Oxford: Oxford University Press, 2020.

Russell, Bertrand. The Problems of Philosophy. Oxford: Oxford University Press, 2001.

Shafer-Landau, Russ. Moral Realism: A Defence. Oxford University Press, 2003. Sinnott-Armstrong, Walter. Moral Skepticisms. Oxford: Oxford University Press, 2006.

Star, Daniel. "Moral Knowledge, Epistemic Externalism, and Intuitionism." Ratio 21, no. 3 (September 2008): 329-43.

Street, Sharon. "A Darwinian Dilemma for Realist Theories of Value." Philosophical Studies 127, no. 1 (January 2006): 109-66.

Steup, Matthias, John Turri, and Ernest Sosa, eds. Contemporary Debates in Epistemology, 2nd ed. Malden, MA: Wiley Blackwell, 2014.

Stroud, Barry. The Significance of Philosophical Scepticism. Oxford: Oxford University Press, 1984.

Sturgeon, Nicholas. "Moral Explanations." In Essays on Moral Realism, edited by Geoffrey Sayre-McCord, 229-55. Ithaca, NY: Cornell University Press, 1988.

Thomasson, Amie. Ontology Made Easy. Oxford: Oxford University Press, 2014. . Ordinary Objects. Oxford: Oxford University Press, 2007.

Van Cleve, James. "Reliability, Justification, and the Problem of Induction." Midwest Studies in Philosophy 9, no. 1 (September 1984): 555-67.

Vavova, Katia. "Debunking Evolutionary Debunking." In Oxford Studies in Metaethics, vol. 6, edited by Russ Shafer-Landau, 76-101. Oxford: Oxford University Press, 2016.

Vogel, Jonathan. "Cartesian Skepticism and Inference to the Best Explanation." Journal of Philosophy 87, no. 11 (November 1990): 658-66.

Wedgwood, Ralph. "Internalism Explained." Philosophy and Phenomenological Research 65, no. 2 (September 2002): 349-69.

. "The Moral Evil Demons." In Disagreement, edited by Richard Feldman and Ted A. Warfield, 216-46. Oxford: Oxford University Press, 2010.

Williamson, Timothy. Knowledge and Its Limits. Oxford: Oxford University Press, 2000.

- "Knowledge First." In Steup, Turri, and Sosa, Contemporary Debates in Epistemology, 1-9. 